\title{
The effect of statins on testosterone in men and women, a systematic review and meta-analysis of randomized controlled trials
}

\author{
C Mary Schooling ${ }^{1,2 *}$, Shiu Lun Au Yeung ${ }^{2}$, Guy Freeman ${ }^{2}$ and Benjamin J Cowling ${ }^{2}$
}

\begin{abstract}
Background: Statins are extensively used for cardiovascular disease prevention. Statins reduce mortality rates more than other lipid-modulating drugs, although evidence from randomized controlled trials also suggests that statins unexpectedly increase the risk of diabetes and improve immune function. Physiologically, statins would be expected to lower androgens because statins inhibit production of the substrate for the local synthesis of androgens and statins' pleiotropic effects are somewhat similar to the physiological effects of lowering testosterone, so we hypothesized that statins lower testosterone.

Methods: A meta-analysis of placebo-controlled randomized trials of statins to test the a priori hypothesis that statins lower testosterone. We searched the PubMed, Medline and ISI Web of Science databases until the end of 2011, using '(Testosterone OR androgen) AND (CS-514 OR statin OR simvastatin OR atorvastatin OR fluvastatin OR lovastatin OR rosuvastatin OR pravastatin)' restricted to randomized controlled trials in English, supplemented by a bibliographic search. We included studies with durations of $2+$ weeks reporting changes in testosterone. Two reviewers independently searched, selected and assessed study quality. Two statisticians independently abstracted and analyzed data, using random or fixed effects models, as appropriate, with inverse variance weighting.

Results: Of the 29 studies identified 11 were eligible. In 5 homogenous trials of 501 men, mainly middle aged with hypercholesterolemia, statins lowered testosterone by $-0.66 \mathrm{nmol} / \mathrm{I}(95 \%$ confidence interval (Cl) -0.14 to -1.18 ). In 6 heterogeneous trials of 368 young women with polycystic ovary syndrome, statins lowered testosterone by -0.40 $\mathrm{nmol} / \mathrm{l}(95 \% \mathrm{Cl}-0.05$ to -0.75$)$. Overall statins lowered testosterone by $-0.44 \mathrm{nmol} / \mathrm{l}(95 \% \mathrm{Cl}-0.75$ to -0.13$)$.
\end{abstract}

Conclusions: Statins may partially operate by lowering testosterone. Whether this is a detrimental side effect or mode of action warrants investigation given the potential implications for drug development and prevention of non-communicable chronic diseases.

See commentary article here http://www.biomedcentral.com/1741-7015/11/58

Keywords: androgen, cardiovascular, cholesterol, diabetes, inflammation, statins, testosterone

\section{Background}

Statins are extensively used in the West for secondary prevention of cardiovascular diseases, and have contributed to a reduction in cardiovascular disease mortality rates. Statin use will become more common globally with the emerging epidemic of cardiovascular disease in developing countries and the increasing availability of

\footnotetext{
* Correspondence: mschooli@hunter.cuny.edu

${ }^{1}$ CUNY School of Public Health at Hunter College, 2180 Third Avenue, New York, NY 10035, USA

Full list of author information is available at the end of the article
}

statins off patent. Randomized controlled trials (RCTs) show statins reduce mortality rates more than other commonly used lipid-modulating therapies $[1,2]$, such as niacin, fibrates and ezetimibe (where the evidence is limited), and are beneficial for some cardiovascular diseases poorly correlated with cholesterol [3], although statins increase the risk of diabetes [4], with a dosedependent effect [5]. In RCTs statins also reduce inflammation [6,7] and improve immune function [8,9]. Currently, there is no known, coherent explanation for this

\section{Biomed Central}


specific pattern of pleiotropic effects, and no identified 'active ingredient', despite relevance to drug discovery, existing therapies and modifiable risk factors.

Statins inhibit the enzyme 3-hydroxy-3-methyl-glutarylCoA (HMG-CoA) reductase, which reduces cholesterol production. In contrast niacin blocks the breakdown of fats, fibrates activate peroxisome proliferator-activated receptor (PPAR)- $\alpha$ and ezetimibe inhibits cholesterol absorption. All modulate circulating lipids, but only statins also inhibit de novo synthesis of cholesterol throughout the body [10]. Concern has always existed that statins might impair testosterone production [11] either by reducing availability of its preferred substrate, that is, locally produced de novo cholesterol in the gonads [12] and elsewhere, or by inhibiting steps in the steroidogenesis process [13], but this concern has been considered of little clinical significance [14-16]. Lowering androgens potentially explains some of statins' effects. An RCT among men found testosterone therapy enhanced glucose metabolism [17], whilst impaired glucose metabolism may be a side effect of androgen deprivation therapy [18]. Men with naturally low androgens due to Klinefelter's syndrome are more prone to diabetes [19]. Extensive experimental evidence indicates that testosterone is immunomodulatory $[20,21]$ and impairs immune response [22,23]. Given statins' physiological mechanism would be expected to reduce androgens as well as the similarity between the effects of statins and of reducing androgens, we hypothesized $a$ priori that the pleiotropic effects of statins could be due to lowering of androgens, that is, that statins lower androgens and that lower androgens might mediate the pleiotropic effects of statins. Here, we carried out a metaanalysis of placebo-controlled randomized trials, to avoid bias by indication, in men and women to examine whether statins reduced total testosterone.

\section{Methods}

We implemented this meta-analysis following the Preferred Reporting Items for Systematic Reviews and MetaAnalyses (PRISMA) checklist (Additional file 1). Two reviewers (CMS and SLAY) independently searched for and selected studies, resolving differences by consensus. Two statisticians (GF and BJC) extracted information from the selected studies.

\section{Data sources and searches}

We systematically searched the PubMed, Medline and ISI Web of Science databases until the end of 2011 using search term '(Testosterone OR androgen) AND (CS-514 OR statin OR simvastatin OR atorvastatin OR fluvastatin OR lovastatin OR rosuvastatin OR pravastatin)' with the search limited to RCTs of studies in humans in English, because an initial search suggested the relevant literature was in English. From our search, we discarded any studies that were not relevant from the title or abstract and read the remaining to identify placebo-controlled randomized trials of statins with testosterone reported. We also used the references of the selected trials to identify additional relevant trials.

\section{Study selection}

We included any published placebo-controlled randomized trial in English of at least 2 weeks' duration examining the effect of statins on testosterone in adults, because statins act rapidly on cholesterol [11]. We did not consider trials in children, because children have different levels of testosterone, and statins are rarely used in children. We did not otherwise select by participant characteristics, because statins are used for the same purpose in a wide variety of patients, and there is no reason to think that statins have different effects by patient subgroup.

\section{Data extraction and quality assessment}

A statistician (GF) extracted information by trial arm on number of participants, testosterone assays used, and mean and standard deviation of the change in testosterone during the trial. Where this information was not provided in full, the statistician (GF) made conservative estimates based on the information available. A second statistician (BJC) then checked the information extracted and any estimates. The reviewers (CMS and SLAY) independently used an established tool to evaluate the quality of each trial [24], and a sensitivity analysis was done excluding the lower quality trials.

\section{Data synthesis and analysis}

We used funnel plots to assess publication bias, and $\mathrm{I}^{2}$ to assess heterogeneity between trials. To obtain an estimate of the difference in mean testosterone between statin and placebo groups, we combined the results of the selected trials using inverse variance weighting and a fixed or random effects model depending on the level of heterogeneity, using the 'metacont' function from the 'meta' package of R 2.14.1 (R Development Core Team, Vienna, Austria). We considered men and women together and separately because of the different hormone milieu by sex. We did no other subgroup analysis.

This study is an analysis of published data, which does not require ethics committee approval.

\section{Results}

The initial searches yielded 27 studies. Two additional trials $[11,25]$ were found from the bibliographic search. We discarded 18 studies. Three were clearly not relevant based on title, four had no control group, three had the control group taking other drugs (namely neomycin, cholestyramine or other lipid-lowering drugs and atorvastatin plus ezetimibe), four were not randomized controlled 
trials of statins, two were largely duplicates of other included publications [26,27] and two provided insufficient information. Details of these 18 excluded studies are given in Additional file 2. Of the 11 trials remaining, 1 small trial of 15 men and 7 women providing only graphs had an implausibly high post-intervention value of testosterone for women in the placebo group (mean approximately $5.2 \mathrm{nmol} / \mathrm{l}$ for 3 women, no standard deviation given) [28], so these 7 women were also excluded. Figure 1 shows the search strategy resulting in these 11 placebo-controlled randomized trials.

Table 1 shows there were 5 trials over 25 years of 501 men, mainly middle aged with hypercholesterolemia, taking typical doses of statins. There were 6 recent trials of 368 young women with polycystic ovary syndrome. Most of the trials were in western settings and were carried out by teams affiliated with or funded by pharmaceutical companies. Most of the trials were of average quality as shown in Additional file 3, with the larger, more recent ones generally of higher quality.

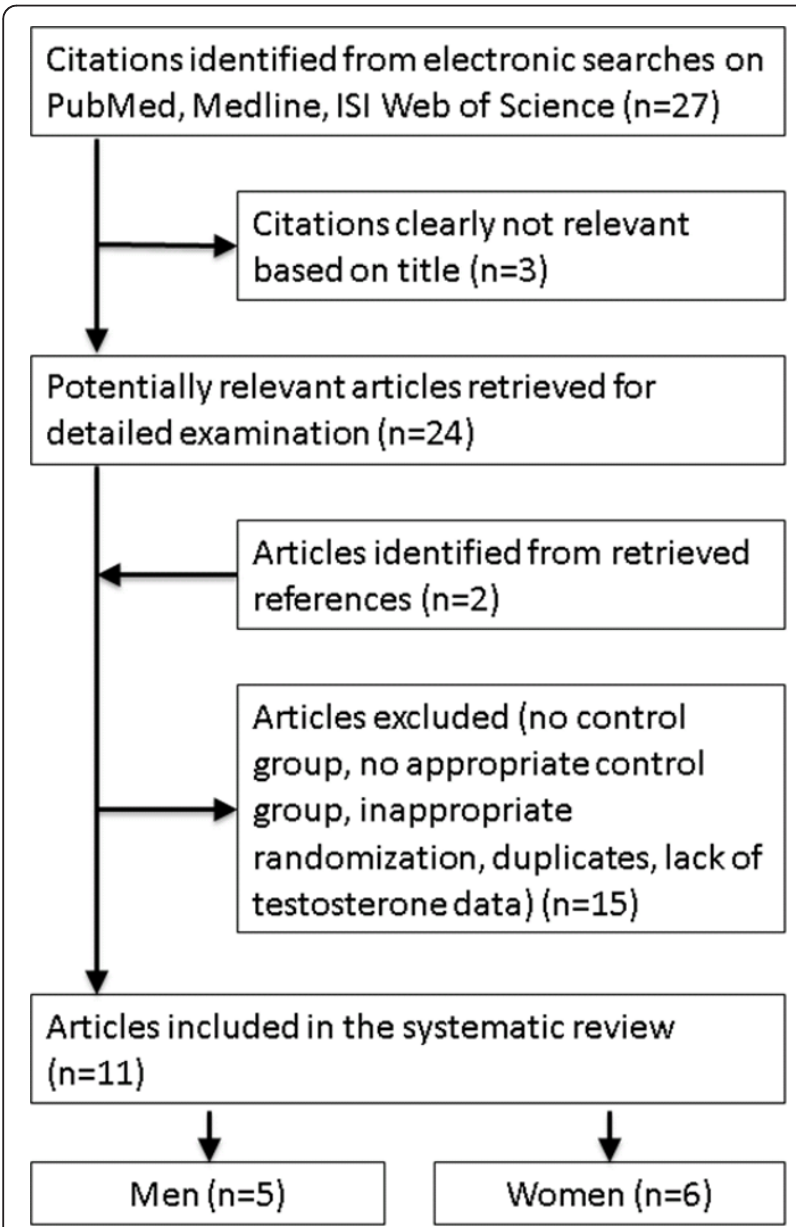

Figure 1 Selection process for the placebo-controlled randomized trials of the effects of statins on testosterone.
Funnel plots gave little indication of publication bias among men (Figure 2), but among women, the trials were more diverse. For completeness Figure 2 also shows the funnel plot for men and women together.

Figure 3 (top panel) shows a forest plot for men. The trials were homogeneous $\left(\mathrm{I}^{2}=0 \%\right)$, with the overall estimate within the confidence intervals of all trials. Statins lowered testosterone by about $3.4 \%$ among men $(-0.66$ $\mathrm{nmol} / \mathrm{l}, 95 \%$ confidence interval $(\mathrm{CI})-0.14$ to -1.18$)$ in both fixed and random effects models, and the estimate was similar $(-0.73 \mathrm{nmol} / \mathrm{l}, 95 \% \mathrm{CI}-0.20$ to -1.26$)$ including only the higher quality trials $[15,16,29]$. Figure 3 (middle panel) shows a forest plot for women. The trials were heterogeneous $\left(\mathrm{I}^{2}=90.1 \%\right)$. Statins lowered testosterone by about $12.3 \%$ among women $(-0.40 \mathrm{nmol} / \mathrm{l}, 95 \%$ CI -0.05 to -0.75$)$ in a random effects model, with similar results when the most extreme study [30] was omitted. The estimate for women was also similar, but included no effect $(-0.50 \mathrm{nmol} / \mathrm{l}, 95 \%$ CI 0.06 to -1.06$)$ when considering only the higher quality trials [30-33]. For completeness, Figure 3 (bottom panel) shows a forest plot for men and women together. The trials were heterogeneous $\left(\mathrm{I}^{2}=79 \%\right)$. Statins lowered testosterone overall $(-0.44$ $\mathrm{nmol} / \mathrm{l}, 95 \% \mathrm{CI}-0.13$ to -0.75 ) in a random effects model; results were similar when each of the three most influential trials was removed, or when only considering the higher quality trials $(-0.57 \mathrm{nmol} / \mathrm{l}, 95 \% \mathrm{CI}-0.12$ to -1.02$)$ [15,16,29-33].

\section{Discussion}

This meta-analysis of placebo-controlled randomized trials suggests statins reduce testosterone. Among men the evidence was homogeneous and largely related to typical doses for the target group using statins for the prevention of cardiovascular disease, where statins potentially lowering testosterone has always been a concern $[11,12,14-16]$. Among women less concern has existed [34]. Very few trials have examined testosterone among women using statins for the prevention of cardiovascular disease, and our findings were less robust for women than men. Nevertheless, statins have recently been discovered as an effective anti-androgen treatment for polycystic ovary syndrome $[25,35]$. A recent metaanalysis of statin therapy for women with polycystic ovary syndrome concluded that statins reduced testosterone based on the same literature [36].

To the best of our knowledge no previous meta-analysis of placebo-controlled randomized trials has assessed the effect of statins on testosterone among men. Two trials comparing simvastatin $80 \mathrm{mg} /$ day with $40 \mathrm{mg} /$ day among in total 640 men found median testosterone lower by $10.3 \%$ and $7.5 \%$ respectively after 48 weeks [34], consistent with the $3.4 \%$ reduction here among 
Table 1 Characteristics of placebo-controlled randomized trials giving the effects of statins on testosterone

\begin{tabular}{|c|c|c|c|c|c|c|c|c|c|c|}
\hline \multirow{3}{*}{$\begin{array}{l}\text { Lead author/ } \\
\text { publicationyear/ } \\
\text { reference }\end{array}$} & \multicolumn{5}{|l|}{ Study } & \multicolumn{4}{|c|}{ Participants } & \multirow{3}{*}{$\begin{array}{l}\text { Authors: funding and } \\
\text { affiliations }\end{array}$} \\
\hline & Setting & Duration & $\begin{array}{l}\text { Statin and daily } \\
\text { dose }\end{array}$ & $\begin{array}{l}\text { Testosterone assessment } \\
\text { method }\end{array}$ & Comments & Men & Women & $\begin{array}{l}\text { Mean } \\
\text { age, } \\
\text { years }\end{array}$ & Health status & \\
\hline & & & & & & \multicolumn{3}{|c|}{$\begin{array}{l}\text { Statin/ } \\
\text { placebo (no. } \\
\text { completed } \\
\text { study) }\end{array}$} & & \\
\hline Tobert 1982 [11] & Europe & 4 weeks & $\begin{array}{l}\text { Lovastatin, multiple } \\
\text { doses }\end{array}$ & Various radio immunoassays & & $\begin{array}{l}47 / \\
10^{\mathrm{a}}\end{array}$ & 0 & 29 & Healthy volunteers & Affiliations include MSD \\
\hline Dobs 2000 [16] & US & 24 weeks & $\begin{array}{l}\text { Simvastatin 20/40 } \\
\text { mg/pravastatin } 40 \\
\text { mg }\end{array}$ & Radio immunoassay & & $\begin{array}{l}85 / \\
28\end{array}$ & 0 & 40 & Hypercholesterolemia & Affiliations include Merck \\
\hline Dobs 2000 [15] & US & 12 weeks & Simvastatin 80 mg & Radio immunoassay & & $\begin{array}{l}37 / \\
39\end{array}$ & 0 & 45 & High LDL cholesterol & Affiliations include Merck \\
\hline Hyyppä 2003 [29] & Finland & 12 weeks & Simvastatin 20 mg & $\begin{array}{l}\text { Direct competitive } \\
\text { immunoassay }\end{array}$ & & $\begin{array}{l}120 / \\
120\end{array}$ & 0 & 48 & Hypercholesterolemia & None given \\
\hline Boehm 2004 [28] & Germany & $\begin{array}{l}3 \\
\text { months }\end{array}$ & Pravastatin $40 \mathrm{mg}$ & $\begin{array}{l}\text { Competitive } \\
\text { electrochemiluminescence } \\
\text { immunoassay }\end{array}$ & & $6 / 9$ & $4 / 3^{b}$ & 65 & Hypercholesterolemia & None given \\
\hline $\begin{array}{l}\text { Banaszewska } 2007 \\
{[26]}\end{array}$ & Poland & 12 weeks & Simvastatin 20 mg & $\begin{array}{l}\text { Specific chemiluminescence } \\
\text { assay }\end{array}$ & $\begin{array}{l}\text { Also using } \\
\text { OCPs }\end{array}$ & 0 & $45 / 48$ & 24 & PCOS & $\mathrm{NIH}$ and drug donations \\
\hline $\begin{array}{l}\text { Banaszewska } 2009 \\
{[27]}\end{array}$ & Poland & $\begin{array}{l}3 \\
\text { months }\end{array}$ & Simvastatin 20 mg & $\begin{array}{l}\text { Specific } \\
\text { electrochemiluminescence } \\
\text { assay }\end{array}$ & $\begin{array}{l}\text { Also using } \\
\text { metformin }\end{array}$ & 0 & $37 / 36$ & 25 & PCOS & $\begin{array}{l}\mathrm{NIH} \text { and Polish State } \\
\text { Committee for Scientific } \\
\text { Research }\end{array}$ \\
\hline Sathyapalan 2009 [30] & UK & 12 weeks & Atorvastatin $20 \mathrm{mg}$ & $\begin{array}{l}\text { Chemiluminescent } \\
\text { immunoassay }\end{array}$ & & 0 & 19/18 & 28 & PCOS & Pfizer \\
\hline Kazerooni 2010 [32] & Iran & 12 weeks & Simvastatin 20 mg & Radio immunoassay & $\begin{array}{l}\text { Also using } \\
\text { metformin }\end{array}$ & 0 & $42 / 42$ & 25 & PCOS & None \\
\hline Raja-Khan 2011 [31] & US & 6 weeks & Atorvastatin $40 \mathrm{mg}$ & Not given & & 0 & $9 / 11^{c}$ & 33 & PCOS & $\begin{array}{l}\text { NIH, Penn State Univeristy, } \\
\text { Pfizer }\end{array}$ \\
\hline Rashidi 2011 [33] & Iran & 8 weeks & Simvastatin 20 mg & Chemiluminescence assay & $\begin{array}{l}\text { Also receiving } \\
\text { IVF treatment }\end{array}$ & 0 & $32 / 29$ & 25 & PCOS & Daru Darman Pars Co. \\
\hline
\end{tabular}

Subjects with missing data excluded, but number excluded not clearly given; at least two from the statin arm were excluded.

${ }^{\text {b}}$ Data not used because of an implausible value for testosterone at study end in the placebo group.

'Two subjects with missing data excluded, but not clear from which arm(s).

IVF = in vitro fertilization; MSD = Merck, Sharp and Dohme; $\mathrm{NIH}=$ National Institute of Health; OCP = oral contraceptives; PCOS = polycystic ovary syndrome 


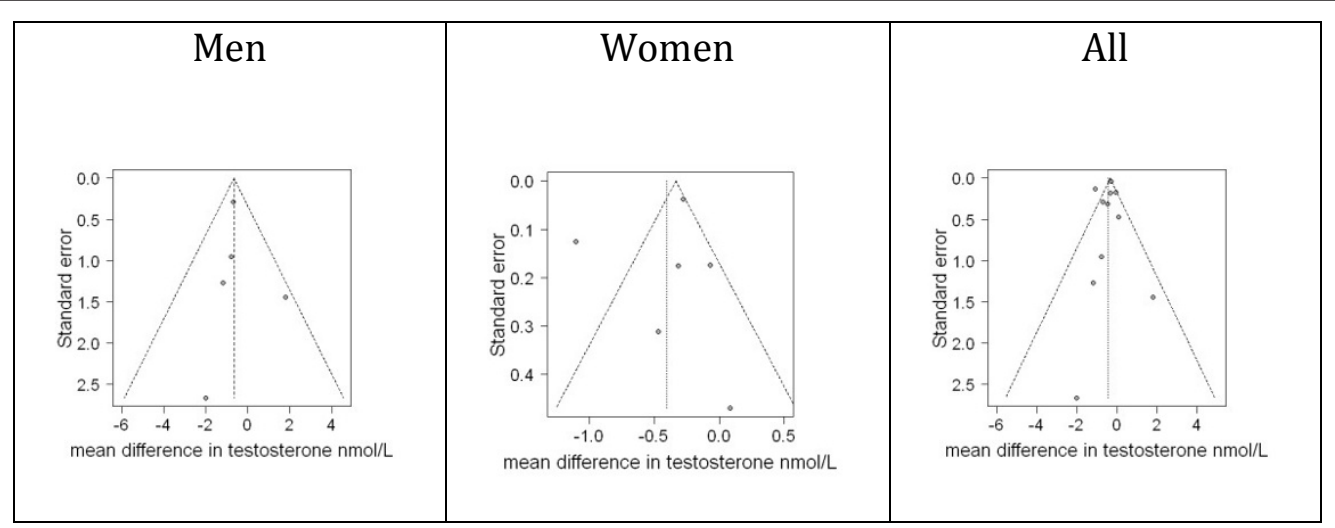

Figure 2 Funnel plots of placebo-controlled randomized trials examining the effects of statins on testosterone by sex and for men and women together.

men mainly using simvastatin $20 \mathrm{mg} /$ day, suggesting a possible dose response of statins on testosterone.

The clinical significance of this reduction in testosterone with statins is difficult to gauge. The normal range of testosterone is wide [37] and sexual function similar across the range [38]. Erectile dysfunction is a rare side effect of statins [39], perhaps because statins' have beneficial effects on cardiovascular function that would counteract changes of this magnitude in testosterone. However, large changes in testosterone (and libido) can occasionally occur with statin use [40], which are reversible by statin withdrawal [40]. The impact on population health may be more germane, where statins causing diabetes could be another side effect. We are not aware of any study examining whether lowering testosterone mediates the effect of statins on diabetes, as this possibility has not, to the best of our knowledge, been considered before, and remains speculative. Moreover, observational studies suggest serum testosterone has sex-specific physiological effects on diabetes, negative among men [41], but positive among women [41], when statins increase diabetes in both sexes $[4,5,42]$. We could not identify any RCT confirming testosterone therapy increases diabetes incidence among women. In postmenopausal women, RCTs of testosterone therapy indicate little effect on glucose metabolism [43]. In younger women, some RCTs indicate that low doses of testosterone may improve glucose metabolism $[44,45]$; female to male transsexuals given high doses of testosterone have improved glucose metabolism [46]. Nevertheless, distinct effects of testosterone on diabetes may occur by dose, sex and age with the reduction in testosterone with statin treatment insufficient to modulate diabetes risk consistently. This metaanalysis also raises the question as to whether lowering testosterone is a side effect of statin therapy or contributes to statins' mode of action, which could inform new treatments and prevention policies. Observationally testosterone is inversely associated with cardiovascular mortality [47]; whether testosterone is causal or a marker of health is unknown [47]. No RCT has shown testosterone therapy reduces cardiovascular events; two RCTs of testosterone therapy were halted because of adverse, mainly cardiovascular events, among men allocated to testosterone $[48,49]$. Natural experiments suggest lower testosterone protects against specifically ischemic heart disease mortality, with a relatively lower risk in men legally castrated [50] or with Klinefelter's syndrome [51]. Physiologically lowering testosterone may reduce thromboxane and platelet activation [52], specifically relevant to reducing ischemic cardiovascular disease but not to diabetes. However, whether lowering testosterone with statin treatment modulates cardiovascular disease, via these or other pathways, has not been examined.

Despite providing a meta-analysis of all known placebocontrolled randomized trials, limitations exist. First, given when they were conducted, not all the trials had high quality scores. However, they had the expected effects on lipids. Second, not all the trials were intended to assess the effects of statins on testosterone. However, the trial, largely designed for this purpose [29], is influential, and alone found statins reduced testosterone [29]. Third, testosterone was not assayed in the same way in all trials (Table 1). Testosterone is difficult to measure, particularly among women. Heterogeneity for women could be due to differing, possibly suboptimal, testosterone assay techniques, for which we compensated by using a random effects model. Imprecision in the assays also reduces power but would not bias a comparison between statin and placebo groups unless statins interfered with the testosterone assay. Steroids can cause assay interference. We could find no evidence that statins cause assay interference. Fourth, too few trials existed to assess dose-response effects or compare 


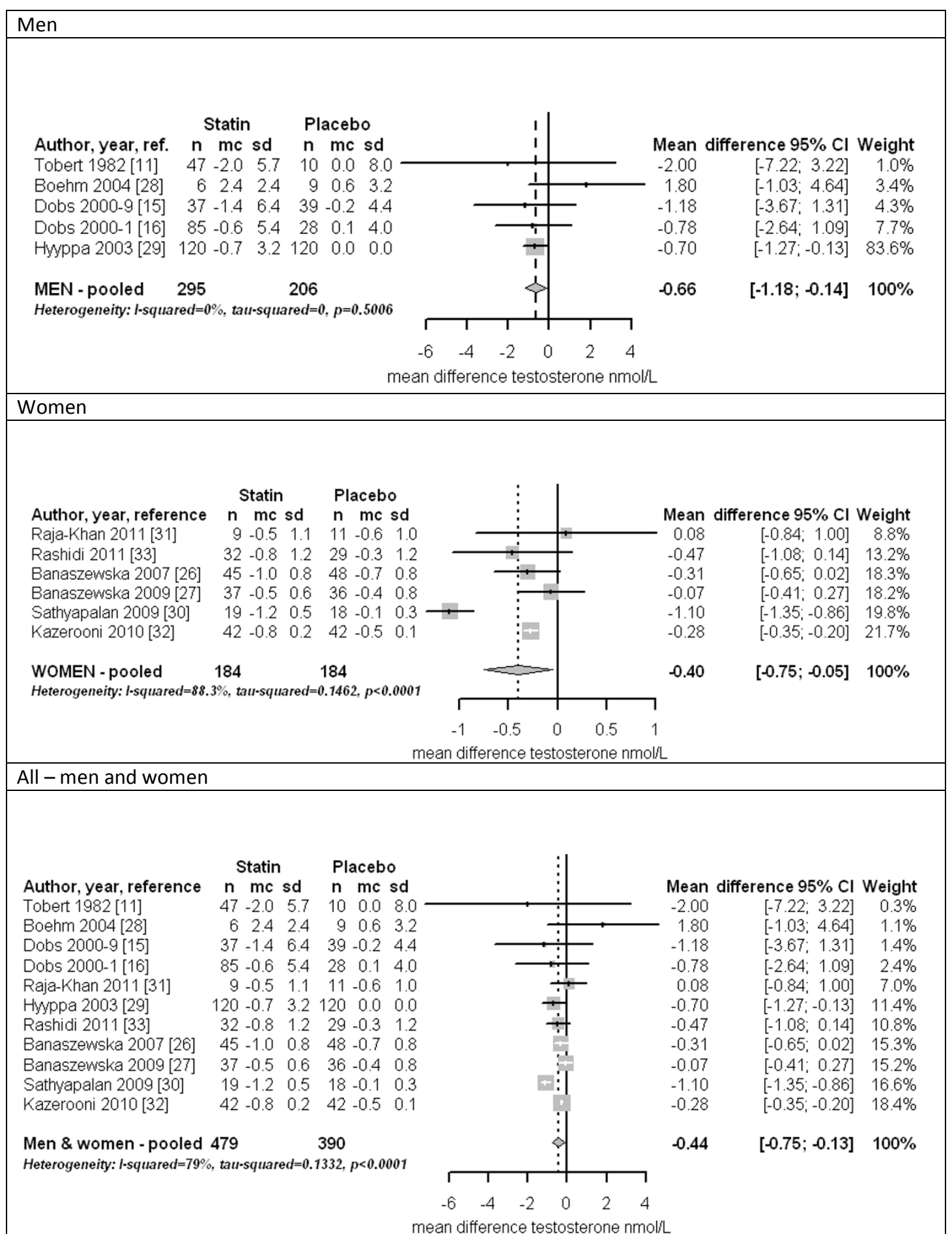

Figure 3 Forest plots of placebo-controlled randomized trials examining the pooled effects of statins on testosterone for men (top panel), women (middle panel) and both sexes (bottom panel). In Kazerooni et al. [32], the reported SD was much smaller than in other trials, whereas the reported SD multiplied by the square root of the sample size was similar to the SDs reported in other trials. If we were to assume that the reported SD was actually the standard error, the pooled estimate for women would be $-0.40 \mathrm{nmol} / \mathrm{l}(95 \% \mathrm{Cl}-0.83 \mathrm{to} 0.03)$ and the overall pooled estimate would be $-0.44 \mathrm{nmol} / \mathrm{l}(95 \% \mathrm{Cl}-0.80$ to -0.08$)$. Mean = mean difference; SD = standard deviation. 
hydrophilic (fluvastatin, rosuvastatin, and pravastatin) to lipophilic (atorvastatin, lovastatin, and simvastatin) statins. However, atorvastatin, pravastatin or simvastatin do not differ substantially in their effects on cardiovascular disease [53]. Fifth, other RCTs may have assessed but not reported the effects of statins on testosterone. Given, the concern that statins lower testosterone [11,12,14-16], these might perhaps be trials where statins reduced testosterone among men. Sixth, RCTs are not always tagged as such and could be missed. To check we searched using 'trial' as a search term instead of restricting the search to RCTs, which gave the same selection (data not shown). Seventh, evidence concerning the effect of statins on testosterone in postmenopausal women is lacking. Eighth, considering the effects of statins on testosterone for men and women together may be invalid, hence results stratified and pooled by sex. Ninth, the effect of statins on testosterone in different ethnic groups is lacking. Effects might differ in settings, such as China, where peak testosterone [37,54], androgen related parameters $[55,56]$ and ischemic heart diseases mortality rates [57] are all lower than in western populations. Finally, cross-sectional studies were not included, because these provide evidence from which it is difficult to assess causality. The larger cross sectional studies only considered men and generally observed lower testosterone among statin users than non-users [58-60].

\section{Conclusions}

This meta-analysis shows that statins reduce testosterone. This finding does not demonstrate that androgens mediate any health effect of statins, but raises the question as to whether testosterone modulation plays a role in statins' effects on health, particularly among men where testosterone is an important hormone. Whether reducing testosterone enhances or impairs the protective effects of statins on cardiovascular mortality needs to be determined urgently, because it could enable the development of enhanced statin based treatments, the development of other drugs in the same class and the identification of potentially modifiable population-wide risk factors for several non-communicable chronic diseases.

\section{Additional material}

Additional file 1: Completed Preferred Reporting Items for Systematic Reviews and Meta-Analyses (PRISMA) checklist for this study. Information as to how this review was conducted.

Additional file 2: Studies excluded after scrutiny with reason for exclusion. A list, with references, of all the studies excluded from this meta-analysis.

Additional file 3: Quality assessment of the selected placebo controlled randomized controlled trials of the effects of statins on testosterone [24]. Quality assessment of each trial.

\section{Abbreviations}

HMG-CoA: 3-hydroxy-3-methyl-glutaryl-CoA reductase; PPAR: peroxisome proliferator-activated receptor; PRISMA: Preferred Reporting Items for Systematic Reviews and Meta-Analyses; RCT: randomized controlled trial.

\section{Authors' contributions}

CMS originated the idea for the paper. CMS and SLAY carried out the systematic search. GF and BJC did the data extraction and analysis. CMS drafted the paper with assistance from SLAY, GF and BJC. All authors reviewed the paper critically and have read and approved the manuscript for publication. All authors had full access to all the data in the study and take responsibility for the integrity of the data and the accuracy of the data analysis. CMS is the guarantor. All authors have read and approved the final manuscript.

\section{Competing interests}

BJC has received research funding from Medlmmune Inc., and consults for Crucell MV. The authors report no other potential conflicts of interest.

\section{Acknowledgements}

We thank Dr Steffie Woolhandler for helpful comments on this paper.

\section{Author details}

${ }^{1}$ CUNY School of Public Health at Hunter College, 2180 Third Avenue, New York, NY 10035, USA. ${ }^{2}$ Department of Community Medicine, School of Public Health, Li Ka Shing Faculty of Medicine, The University of Hong Kong, Units 624-627, Core F, Cyberport 3, 100 Cyberport Road, Hong Kong, Hong Kong SAR, China.

Received: 31 July 2012 Accepted: 28 February 2013

Published: 28 February 2013

\section{References}

1. Studer M, Briel M, Leimenstoll B, Glass TR, Bucher HC: Effect of different antilipidemic agents and diets on mortality: a systematic review. Arch Intern Med 2005, 165:725-730.

2. Gotto AM Jr, Moon JE: Recent clinical studies of the effects of lipidmodifying therapies. Am J Cardiol 2012, 110:15A-26A.

3. Antonopoulos AS, Margaritis M, Lee R, Channon K, Antoniades C: Statins as anti-inflammatory agents in atherogenesis: molecular mechanisms and lessons from the recent clinical trials. Curr Pharm Des 2012, 18:1519-1530.

4. Sattar N, Preiss D, Murray HM, Welsh P, Buckley BM, de Craen AJ, Seshasai SR, McMurray JJ, Freeman DJ, Jukema JW, Macfarlane PW, Packard CJ, Stott DJ, Westendorp RG, Shepherd J, Davis BR, Pressel SL, Marchioli R, Marfisi RM, Maggioni AP, Tavazzi L, Tognoni G, Kjekshus J, Pedersen TR, Cook TJ, Gotto AM, Clearfield MB, Downs JR, Nakamura H, Ohashi Y, et al: Statins and risk of incident diabetes: a collaborative meta-analysis of randomised statin trials. Lancet 2010, 375:735-742.

5. Preiss D, Seshasai SR, Welsh P, Murphy SA, Ho JE, Waters DD, DeMicco DA, Barter P, Cannon CP, Sabatine MS, Braunwald E, Kastelein JJ, de Lemos JA, Blazing MA, Pedersen TR, Tikkanen MJ, Sattar N, Ray KK: Risk of incident diabetes with intensive-dose compared with moderate-dose statin therapy: a meta-analysis. JAMA 2011, 305:2556-2564.

6. Ridker PM, Danielson E, Fonseca FA, Genest J, Gotto AM Jr, Kastelein JJ, Koenig W, Libby P, Lorenzatti AJ, MacFadyen JG, Nordestgaard BG, Shepherd J, Willerson JT, Glynn RJ: Rosuvastatin to prevent vascular events in men and women with elevated C-reactive protein. N Engl $J$ Med 2008, 359:2195-2207.

7. Deng J, Wu Q, Liao Y, Huo D, Yang Z: Effect of statins on chronic inflammation and nutrition status in renal dialysis patients: a systematic review and meta-analysis. Nephrology (Carlton) 2012, 17:545-551.

8. Lee PY, Scumpia PO, Byars JA, Kelly KM, Zhuang H, Shuster JS, Theriaque DW, Segal MS, Reeves WH, Brantly ML: Short-term atorvastatin treatment enhances specific antibody production following tetanus toxoid vaccination in healthy volunteers. Vaccine 2006, 24:4035-4040.

9. Shyamsundar M, McKeown ST, O'Kane CM, Craig TR, Brown V, Thickett DR, Matthay MA, Taggart CC, Backman JT, Elborn JS, McAuley DF: Simvastatin decreases lipopolysaccharide-induced pulmonary inflammation in healthy volunteers. Am J Respir Crit Care Med 2009, 179:1107-1114. 
10. Parker RA, Clark RW, Sit SY, Lanier TL, Grosso RA, Wright JJ: Selective inhibition of cholesterol synthesis in liver versus extrahepatic tissues by HMG-CoA reductase inhibitors. J Lipid Res 1990, 31:1271-1282.

11. Tobert JA, Bell GD, Birtwell J, James I, Kukovetz WR, Pryor JS, Buntinx A, Holmes IB, Chao YS, Bolognese JA: Cholesterol-lowering effect of mevinolin, an inhibitor of 3-hydroxy-3-methylglutaryl-coenzyme a reductase, in healthy volunteers. J Clin Invest 1982, 69:913-919.

12. Dobs AS, Sarma PS, Schteingart D: Long-term endocrine function in hypercholesterolemic patients treated with pravastatin, a new 3hydroxy-3-methylglutaryl coenzyme A reductase inhibitor. Metabolism 1993, 42:1146-1152.

13. Smals AG, Weusten JJ, Benraad TJ, Kloppenborg PW: The HMG-CoA reductase inhibitor simvastatin suppresses human testicular testosterone synthesis in vitro by a selective inhibitory effect on 17-ketosteroidoxidoreductase enzyme activity. J Steroid Biochem Mol Biol 1991, 38:465-468.

14. MacDonald JS, Gerson RJ, Kornbrust DJ, Kloss MW, Prahalada S, Berry PH, Alberts AW, Bokelman DL: Preclinical evaluation of lovastatin. Am J Cardiol 1988, 62:16J-27J.

15. Dobs AS, Schrott H, Davidson MH, Bays H, Stein EA, Kush D, Wu M, Mitchel $Y$, Illingworth RD: Effects of high-dose simvastatin on adrenal and gonadal steroidogenesis in men with hypercholesterolemia. Metabolism 2000, 49:1234-1238.

16. Dobs AS, Miller S, Neri G, Weiss S, Tate AC, Shapiro DR, Musliner TA: Effects of simvastatin and pravastatin on gonadal function in male hypercholesterolemic patients. Metabolism 2000, 49:115-121.

17. Jones TH, Arver S, Behre HM, Buvat J, Meuleman E, Moncada I, Morales AM, Volterrani M, Yellowlees A, Howell JD, Channer KS: Testosterone replacement in hypogonadal men with type 2 diabetes and/or metabolic syndrome (the TIMES2 study). Diabetes Care 2011, 34:828-837.

18. Levine GN, D'Amico AV, Berger P, Clark PE, Eckel RH, Keating NL, Milani RV Sagalowsky Al, Smith MR, Zakai N: Androgen-deprivation therapy in prostate cancer and cardiovascular risk: a science advisory from the American Heart Association, American Cancer Society, and American Urological Association: endorsed by the American Society for Radiation Oncology. CA Cancer J Clin 2010, 60:194-201.

19. Groth KA, Skakkebaek A, Host C, Gravholt CH, Bojesen A: Klinefelter syndrome - a clinical update. J Clin Endocrinol Metab 2013, 98:20-30.

20. Grossman CJ: Interactions between the gonadal steroids and the immune system. Science 1985, 227:257-261.

21. Sakiani S, Olsen NJ, Kovacs WJ: Gonadal steroids and humoral immunity. Nat Rev Endocrinol 2012, 9:56-62.

22. Snider H, Lezama-Davila C, Alexander J, Satoskar AR: Sex hormones and modulation of immunity against leishmaniasis. Neuroimmunomodulation 2009, 16:106-113.

23. Pergola C, Rogge A, Dodt G, Northoff H, Weinigel C, Barz D, Radmark O, Sautebin L, Werz O: Testosterone suppresses phospholipase D, causing sex differences in leukotriene biosynthesis in human monocytes. FASEB $J$ 2011, 25:3377-3387.

24. Verhagen AP, de Vet HC, de Bie RA, Kessels AG, Boers M, Bouter LM, Knipschild PG: The Delphi list: a criteria list for quality assessment of randomized clinical trials for conducting systematic reviews developed by Delphi consensus. J Clin Epidemiol 1998, 51:1235-1241.

25. Duleba AJ, Banaszewska B, Spaczynski RZ, Pawelczyk L: Simvastatin improves biochemical parameters in women with polycystic ovary syndrome: results of a prospective, randomized trial. Fertil Steril 2006, 85:996-1001.

26. Banaszewska B, Pawelczyk L, Spaczynski RZ, Dziura J, Duleba AJ: Effects of simvastatin and oral contraceptive agent on polycystic ovary syndrome: prospective, randomized, crossover trial. J Clin Endocrinol Metab 2007, 92:456-461.

27. Banaszewska B, Pawelczyk L, Spaczynski RZ, Duleba AJ: Comparison of simvastatin and metformin in treatment of polycystic ovary syndrome: prospective randomized trial. J Clin Endocrinol Metab 2009, 94:4938-4945.

28. Bohm M, Herrmann W, Wassmann S, Laufs U, Nickenig G: Does statin therapy influence steroid hormone synthesis? Z Kardiol 2004, 93:43-48.

29. Hyyppa MT, Kronholm E, Virtanen A, Leino A, Jula A: Does simvastatin affect mood and steroid hormone levels in hypercholesterolemic men? A randomized double-blind trial. Psychoneuroendocrinology 2003, 28:181-194.
30. Sathyapalan T, Kilpatrick ES, Coady AM, Atkin SL: The effect of atorvastatin in patients with polycystic ovary syndrome: a randomized double-blind placebo-controlled study. J Clin Endocrinol Metab 2009, 94:103-108.

31. Raja-Khan N, Kunselman AR, Hogeman CS, Stetter CM, Demers LM, Legro RS: Effects of atorvastatin on vascular function, inflammation, and androgens in women with polycystic ovary syndrome: a double-blind, randomized, placebo-controlled trial. Fertil Steril 2011, 95:1849-1852.

32. Kazerooni T, Shojaei-Baghini A, Dehbashi S, Asadi N, Ghaffarpasand F, Kazerooni Y: Effects of metformin plus simvastatin on polycystic ovary syndrome: a prospective, randomized, double-blind, placebo-controlled study. Fertil Steril 2010, 94:2208-2213.

33. Rashidi B, Abediasl J, Tehraninejad E, Rahmanpour H, Sills ES: Simvastatin effects on androgens, inflammatory mediators, and endogenous pituitary gonadotropins among patients with PCOS undergoing IVF: results from a prospective, randomized, placebo-controlled clinical trial. J Investig Med 2011, 59:912-916.

34. Ose L, Davidson MH, Stein EA, Kastelein JJ, Scott RS, Hunninghake DB, Campodonico S, Insull W, Escobar ID, Schrott HG, Stepanavage ME, Wu M, Tate AC, Melino MR, Mercuri M, Mitchel YB: Lipid-altering efficacy and safety of simvastatin $80 \mathrm{mg} /$ day: long-term experience in a large group of patients with hypercholesterolemia. World Wide Expanded Dose Simvastatin Study Group. Clin Cardiol 2000, 23:39-46.

35. Gao L, Zhao FL, Li SC: Statin is a reasonable treatment option for patients with Polycystic Ovary Syndrome: a meta-analysis of randomized controlled trials. Exp Clin Endocrinol Diabetes 2012, 120:367-375.

36. Raval AD, Hunter T, Stuckey B, Hart RJ: Statins for women with polycystic ovary syndrome not actively trying to conceive. Cochrane Database Syst Rev 2011, 10:CD008565.

37. Bhasin S, Pencina M, Jasuja GK, Travison TG, Coviello A, Orwoll E, Wang PY, Nielson C, Wu F, Tajar A, Labrie F, Vesper H, Zhang A, Ulloor J, Singh R, D'Agostino R, Vasan RS: Reference ranges for testosterone in men generated using liquid chromatography tandem mass spectrometry in a community-based sample of healthy nonobese young men in the Framingham Heart Study and applied to three geographically distinct cohorts. J Clin Endocrinol Metab 2011, 96:2430-2439.

38. Bancroft J: The endocrinology of sexual arousal. J Endocrinol 2005, 186:411-427

39. Do C, Huyghe E, Lapeyre-Mestre M, Montastruc $\lrcorner$, Bagheri $\mathrm{H}$ : Statins and erectile dysfunction: results of a case/non-case study using the French Pharmacovigilance System Database. Drug Saf 2009, 32:591-597.

40. de Graaf L, Brouwers AH, Diemont WL: Is decreased libido associated with the use of HMG-CoA-reductase inhibitors? Br J Clin Pharmacol 2004, 58:326-328.

41. Ding EL, Song Y, Malik VS, Liu S: Sex differences of endogenous sex hormones and risk of type 2 diabetes: a systematic review and metaanalysis. JAMA 2006, 295:1288-1299.

42. Culver AL, Ockene IS, Balasubramanian R, Olendzki BC, Sepavich DM, Wactawski-Wende J, Manson JE, Qiao Y, Liu S, Merriam PA, Rahilly-Tierny C, Thomas F, Berger JS, Ockene JK, Curb JD, Ma Y: Statin use and risk of diabetes mellitus in postmenopausal women in the Women's Health Initiative. Arch Intern Med 2012, 172:144-152.

43. Davis SR, Braunstein GD: Efficacy and safety of testosterone in the management of hypoactive sexual desire disorder in postmenopausal women. J Sex Med 2012, 9:1134-1148.

44. Herbst KL, Calof OM, Hsia SH, Sinha-Hikim I, Woodhouse LJ, Buchanan TA, Bhasin S: Effects of transdermal testosterone administration on insulin sensitivity, fat mass and distribution, and markers of inflammation and thrombolysis in human immunodeficiency virus-infected women with mild to moderate weight loss. Fertil Steril 2006, 85:1794-1802.

45. Miller KK, Biller BM, Schaub A, Pulaski-Liebert K, Bradwin G, Rifai N, Klibanski A: Effects of testosterone therapy on cardiovascular risk markers in androgen-deficient women with hypopituitarism. J Clin Endocrinol Metab 2007, 92:2474-2479.

46. Giltay EJ, Toorians AW, Sarabdjitsingh AR, de Vries NA, Gooren LJ: Established risk factors for coronary heart disease are unrelated to androgen-induced baldness in female-to-male transsexuals. J Endocrinol 2004, 180:107-112

47. Araujo AB, Dixon JM, Suarez EA, Murad MH, Guey LT, Wittert GA: Clinical review: Endogenous testosterone and mortality in men: a systematic review and meta-analysis. J Clin Endocrinol Metab 2011, 96:3007-3019. 
48. Testosterone treatment of men with alcoholic cirrhosis: a double-blind study. The Copenhagen Study Group for Liver Diseases. Hepatology 1986, 6:807-813.

49. Basaria S, Coviello AD, Travison TG, Storer TW, Farwell WR, Jette AM, Eder R, Tennstedt S, Ulloor J, Zhang A, Choong K, Lakshman KM, Mazer NA, Miciek R, Krasnoff J, Elmi A, Knapp PE, Brooks B, Appleman E, Aggarwal S, Bhasin G, Hede-Brierley L, Bhatia A, Collins L, LeBrasseur N, Fiore LD, Bhasin S: Adverse events associated with testosterone administration. N Engl J Med 2010, 363:109-122.

50. Eyben FE, Graugaard C, Vaeth M: All-cause mortality and mortality of myocardial infarction for 989 legally castrated men. Eur J Epidemiol 2005, 20:863-869.

51. Swerdlow AJ, Higgins CD, Schoemaker MJ, Wright AF, Jacobs PA: Mortality in patients with Klinefelter syndrome in Britain: a cohort study. J Clin Endocrinol Metab 2005, 90:6516-6522.

52. Ajayi AA, Mathur R, Halushka PV: Testosterone increases human platelet thromboxane A2 receptor density and aggregation responses. Circulation 1995, 91:2742-2747.

53. Mills EJ, Wu P, Chong G, Ghement I, Singh S, Akl EA, Eyawo O, Guyatt G, Berwanger $\mathrm{O}$, Briel M: Efficacy and safety of statin treatment for cardiovascular disease: a network meta-analysis of 170,255 patients from 76 randomized trials. QJM 2011, 104:109-124.

54. Li JY, Li XY, Li M, Zhang GK, Ma FL, Liu ZM, Zhang NY, Meng P: Decline of serum levels of free testosterone in aging healthy Chinese men. Aging Male 2005, 8:203-206.

55. Johnson L, Barnard JJ, Rodriguez L, Smith EC, Swerdloff RS, Wang XH, Wang C: Ethnic differences in testicular structure and spermatogenic potential may predispose testes of Asian men to a heightened sensitivity to steroidal contraceptives. J Androl 1998, 19:348-357.

56. Jin B, Turner L, Zhou Z, Zhou EL, Handelsman DJ: Ethnicity and migration as determinants of human prostate size. J Clin Endocrinol Metab 1999, 84:3613-3619

57. Mirzaei M, Truswell AS, Taylor R, Leeder SR: Coronary heart disease epidemics: not all the same. Heart 2009, 95:740-746.

58. Hall SA, Page ST, Travison TG, Montgomery RB, Link CL, McKinlay JB: Do statins affect androgen levels in men? Results from the Boston area community health survey. Cancer Epidemiol Biomarkers Prev 2007. 16:1587-1594

59. Stanworth RD, Kapoor D, Channer KS, Jones TH: Statin therapy is associated with lower total but not bioavailable or free testosterone in men with type 2 diabetes. Diabetes Care 2009, 32:541-546.

60. Akduman B, Tandberg DJ, O'Donnell Cl, Hughes A, Moyad MA, Crawford ED: Effect of statins on serum prostate-specific antigen levels. Urology 2010, 76:1048-1051.

Pre-publication history

The pre-publication history for this paper can be accessed here: http://www.biomedcentral.com/1741-7015/11/57/prepub

doi:10.1186/1741-7015-11-57

Cite this article as: Schooling et al.: The effect of statins on testosterone in men and women, a systematic review and meta-analysis of randomized controlled trials. BMC Medicine 2013 11:57.

\section{Submit your next manuscript to BioMed Central and take full advantage of:}

- Convenient online submission

- Thorough peer review

- No space constraints or color figure charges

- Immediate publication on acceptance

- Inclusion in PubMed, CAS, Scopus and Google Scholar

- Research which is freely available for redistribution

Submit your manuscript at www.biomedcentral.com/submit 